\title{
SIGNIFICADO DO FRACASSO ESCOLAR PARA OS ATORES SOCIAIS QUE UTILIZAM O PROGRAMA DE ASSISTÊNCIA PRIMÁRIA DE SAÚDE ESCOLAR — PROASE NO MUNICÍPIO DE RIBEIRÃO PRETO*
}

\author{
Maria das Graças Carvalho Ferriani** \\ Marta Angélica Iossi***
}

FERRIANI, M.G.C.; IOSSI, M.A. Significado do fracasso escolar para os atores sociais que utilizam o programa de assistência primária de saúde escolar - PROASE no município de Ribeirão Preto. Rev. latino-am.enfermagem, Ribeirão Preto, v.6, n. 5, p. 35-44, dezembro 1998.

O presente estudo tem como objetivo identificar e analisar o significado do fracasso escolar para os atores sociais que utilizam o Programa de Assistência Primária de Saúde Escolar - PROASE (familiares, profissionais da educação e da saúde) que atuam no Programa, articulando o discurso desses atores com o oficial, visando subsidiar ações futuras para o Programa. O nosso estudo utiliza como referencial teórico, a pesquisa qualitativa, fundamentada em MINAYO (1992). Foi escolhida uma área em que o PROASE desenvolve suas atividades e, através da técnica de entrevista semi-estruturada e análise de documentos, foi possivel conhecer como os três segmentos, que fazem parte da amostra, entendem o significado do fracasso escolar.

UNITERMOS: baixo rendimento escolar, ocupações em saúde, escolares, enfermagem

\section{INTRODUÇÃO}

A Saúde Escolar desde a sua gênese "tem sido atravessada por inúmeros questionamentos que vão desde críticas e equívocos cometidos nesta área, até a proposta de sua extinção" (FERRIANI \& GOMES, 1997, p. 1).

Nosso interesse em pesquisar a criança em idade escolar adveio de nossa experiência prática como uma das coordenadoras de um Programa de Assistência Primária de Saúde Escolar (PROASE), implantado em 1985, no município de Ribeirão Preto, através de convênio celebrado entre a Escola de Enfermagem de Ribeirão Preto da Universidade de São Paulo, Fundação de Assistência ao Estudante (FAE) e a Prefeitura Municipal de Ribeirão Preto, junto às escolas da Rede Oficial de Ensino do nosso município.

O PROASE tem como objetivos:

- Promover a atenção integral à saúde do escolar, compreendendo ações de promoção, preservação e recuperação da saúde, através dos próprios alunos e professores da rede de serviços e da ação integrada entre os órgãos dos setores saúde e educação.

- Contribuir para melhoria de saúde e, conseqüentemente, do processo de desenvolvimento e formação integral da criança.

- Analisar o processo de trabalho em saúde na assistência ao escolar, entendendo-se não como assistência a uma determinada faixa etária, mas como assistência a saúde mediada pelo setor de Educação abrangendo do préescolar ao adolescente (FERRIANI \& CANO, 1992, p.1).

As atividades são desenvolvidas em escolas, Unidades Básicas de Saúde (UBS) e em cinco (05) Unidades Distritais de Saúde (UBDS), onde se localizam os Ambulatórios de Saúde Escolar e o Laboratório Óptico.

Esse programa, sob nossa coordenação, ampliouse gradativamente ao longo desses anos e atualmente conta com uma equipe de sessenta e seis (66) profissionais de saúde e educação (enfermeiros, auxiliares de enfermagem, psicólogos, fonoaudiólogos, pediatras, dentre outros) que atendem noventa e duas escolas e aproximadamente noventa mil escolares com idade entre

\footnotetext{
* Este trabalho é parte da Tese de Livre-Docência de:

FERRIANI, M.G.C. Percepções dos atores sociais que utilizam o Programa de Assistência Primária de Saúde Escolar —- PROASE no município de Ribeirão Preto: análise crítica. Ribeirão Preto, 120p. Tese (Livre-Docência). Escola de Enfermagem de Ribeirão Preto da Universidade de São Paulo

** Professora Associada do Departamento de Enfermagem Materno-Infantil e Saúde Pública da Escola de Enfermagem de Ribeirão Preto da Universidade de São Paulo

*** Enfermeira da Secretaria Municipal da Saúde de Ribeirão Preto
} 
cinco a onze anos.

Em 1992, foi montada uma Unidade de Referência do PROASE para o município nas especialidades de oftalmologia e otorrinolaringologia. $\mathrm{O}$ PROASE conta com um Laboratório Óptico, para atender as famílias de alunos que necessitam de óculos.

Após esse primeiro momento, o Programa foi sendo ampliado gradativamente na rede, criando novos espaços, de acordo com as necessidades da população alvo. Com essa ampliação (a Vigilância à Saúde nas escolas e ambulatórios especializados com atendimentos em psicologia, fonoaudiologia, oftalmologia, dentre outros) emergiram muitos questionamentos em relação às ações da saúde escolar e quanto ao direcionamento do Programa.

Um dos problemas, com o qual temos nos deparado durante nossa prática com escolares e familiares, refere-se à vivência da problemática do "fracasso escolar" em seu cotidiano.

Ao analisarmos os dados estatísticos, percebemos que tanto a evasão como a repetência nas escolas públicas é elevada. Os altos índices de evasão e repetência, no decorrer da década de 80 , demonstram que apenas $20 \%$ dos alunos matriculados na primeira série do primeiro grau concluíram a oitava série. Em 1990, o IBGE confirmou que somente $26,5 \%$ dos adolescentes brasileiros tinham este ou maior nível de instrução (FUNDAÇÃO INSTITUTO BRASILEIRO DE GEOGRAFIA E ESTATÍSTICA, 1992).

Em Ribeirão Preto, segundo a Delegacia de Ensino, o índice de repetência no primeiro grau atinge $11 \%$ e no segundo grau é de $2 \%$. Os índices de evasão escolar alcançam $8,4 \%$ no primeiro grau e $21 \%$ no segundo grau (Folha de São Paulo, 1996).

Outra questão é que as ações dos Programas de Saúde Escolar têm sido desenvolvidas para a população que freqüenta a escola, partindo-se do pressuposto que existem condições de acesso universal e igualdades de oportunidades no processo de escolarização. Entretanto, o que ocorre, na prática, é que milhares de crianças se encontram fora do sistema educacional, seja porque não entram, seja porque evadiram-se da escola. Esta seleção de clientela a ser atendida acaba realizando uma dupla exclusão: a criança excluída do direito à assistência de saúde e educação.

Se o escolar for pobre, a relação "fracasso escolar" e "desnutrição" é imediata e mecânica. E mais, em se tratando de Saúde Escolar já se tem como pressuposto que se está falando de doença, porque essas crianças não conseguem aprender. Tal limitação nos mostrou a necessidade de aprofundarmos os conhecimentos de saúde destas crianças, entendendo a fusão do biológico com o social.

Temos observado que os escolares e os adolescentes têm os mesmos determinantes de saúde da população, com um perfil bastante semelhante. Em decorrência dos altos índices de mortalidade infantil em nosso país, o setor saúde tem priorizado os Programas de Assistência Materno-Infantil. A mortalidade na faixa etária do escolar é baixa, sendo os acidentes a principal causa de morte.

HARADA (1993) chama a atenção em seu estudo para o exame clínico realizado no ingressante em seu Programa de Saúde Escolar na cidade de Embu-SP onde apresenta uma elevada taxa de morbidade, com alta prevalência de doenças infecto-parasitárias típica de comunidades de baixo nível socioeconômico. Observou também a presença de alterações de etiologia congênita e do grupo de doenças endócrinas, metabólicas, nutricionais e imunológicas, sendo que muitas destas alterações poderiam ter sido diagnosticadas mais precocemente. A saúde e a educação muitas vezes querem tratar o fracasso escolar como uma doença, através de ferramentas que não são capazes de reverter o quadro, problema com o qual, a realidade brasileira vem convivendo há anos. Observamos que desse quadro de alterações há outros aspectos que extrapolam estas duas práticas sociais, ou seja, Saúde e Educação.

PATTO (1990), preocupada com a Produção do Fracasso Escolar, faz uma revisão na literatura sobre as causas das desigualdades educacionais na sociedade brasileira e uma análise das raízes históricas das concepções sobre o fracasso escolar das crianças dos segmentos mais pobres da população.

Complementa sua pesquisa com observações em vários contextos e entrevistas formais e informais com todos os envolvidos no processo educativo que se desenrola numa escola de $1^{\circ}$ grau: a escola que não aceita a criança como é e a criança que não aceita a escola como funciona. A autora chama atenção entre as conclusões ou confirmações que o estudo permitiu destacando quatro aspectos, pelo caráter fundamental de que se revestem:

1. As explicações do fracasso escolar baseadas nas teorias do déficit e da diferença cultural precisam ser vistas a partir do conhecimento dos mecanismos escolares produtores de dificuldades de aprendizagem.

2. O fracasso da escola pública elementar é o resultado inevitável de um sistema educacional gerador de obstáculos a realização de seus objetivos.

3. O fracasso da escola elementar é administrado por um discurso científico que estudado em sua competência, naturaliza esse fracasso aos olhos de todos os envolvidos no processo.

4. A convivência de mecanismos de neutralização dos conflitos com manifestações de insatisfação e rebeldia faz da escola um lugar propício à passagem ao compromisso humano genérico, (PATTO, 1990, p.34049). 
COLLARES \& MOYSÉS (1992) ressaltaram a importância do fator pedagógico como determinante no processo do fracasso escolar, na medida em que ele está vinculado a fatores internos da instituição escolar como formação profissional, o planejamento do ano letivo, a inadequação curricular e a metodologia do processo de ensino-aprendizagem.

O setor da saúde não pode buscar a resolução dos problemas de aprendizagem através de um modelo clínico tradicional, individual e biológico, com conseqüente medicalização desta questão, pois desta forma, tenta-se localizar o problema exclusivamente na criança, explicando-o através de relações lineares e simplistas da ocorrência de doenças, isentando as responsabilidades do sistema educacional e da sociedade.

HARADA (1993) constatou também que o perfil de morbidade encontrado entre as crianças encaminhadas pela equipe de saúde foram alterações predominantemente orgânicas, enquanto que os quadros de cefaléia, distúrbios de aprendizagem, comportamento, linguagem escrita compuseram uma parcela importante do perfil de morbidade dos casos encaminhados pelos professores, demonstrando dessa forma uma diferença desses encaminhamentos entre os profissionais da área de saúde e da educação.

Por outro lado, sabemos que a escola, independente de concepções político-educacionais e até mesmo apesar destas, é um espaço importante para a vida de crianças e adolescentes.

Se é verdade que a escola é importante para o desenvolvimento de pessoas, a família em geral é apontada como um fator fundamental na vida do ser humano. Como exemplo dessa abordagem citamos MINUCHIM (1990) e KNOBEL (1992), que assinalam a família como a matriz do desenvolvimento psicossocial de seus membros e que determina a estes o cunho da individualidade. Estes autores dimensionam que é no âmago da família que o ser humano se constrói, socializa e humaniza, na proporção em que são satisfeitas suas necessidades, permitindo-se o desenvolvimento da personalidade em sua plenitude.

MINUCHIM (1990) também aponta que a família, ao sofrer influências da sociedade muda, se adapta e se reestrutura às circunstâncias históricas, de maneira a manter a continuidade e a intensificar o crescimento psicossocial de cada membro.

Em relação à responsabilidade do cuidado e educação dos filhos, vistos no âmbito da família, PARKER (1991) aponta que, independentemente da cultura ou região, esta destina-se fundamentalmente às mulheres. É por intervenção da mãe ou da mulher equivalente a ela, como a avó, ou a tia ou a babá que se organiza a mais precoce relação da criança com a realidade.

Complementando esta idéia, recorremos a KNOBEL (1992), que chama a atenção para o fato de que a família é o núcleo da sociedade. O autor observa que é na família que se aprendem hábitos de vida, produto de uma convivência natural, e que a compreensão das reais necessidades dos jovens é imprescindível à prevenção de muitos problemas como por exemplo a violência.

Para melhor compreensão destas questões levantadas na literatura específica e na nossa vivência prática, interessa-nos identificar, conhecer e analisar o significado do fracasso escolar para os atores sociais que utilizam o PROASE (pais, profissionais da educação e da saúde que atuam no Programa) articulando o discurso desses atores com o discurso oficial, com vistas a subsidiar ações futuras para o Programa.

No sentido de melhor operacionalizar esse objetivo, voltamo-nos para a seguinte questão: Qual é o significado do fracasso escolar para os atores sociais? O nosso objetivo e a questão levantada partiram de pressupostos que orientam este estudo relacionado à utilização do Programa de Saúde Escolar na escola e na UBDS, onde funcionam os ambulatórios de saúde escolar.

Pressupomos que as crianças que freqüentam os ambulatórios de saúde escolar necessitam realmente desse atendimento proposto pelo PROASE. Presumimos, entretanto, que, embora seja essa a intenção, o Programa vem criando falsas demandas.

\section{METODOLOGIA}

\section{Referencial teórico-metodológico}

A nossa investigação utiliza a pesquisa qualitativa, definida por MINAYO \& SANCHES (1993) como aquela capaz de aprofundar a complexidade de fenômenos fatos e processos particulares e específicos de grupos mais ou menos delimitados em extensão capazes de serem abrangidos intensamente.

Compreendendo a Pesquisa Qualitativa como sendo aquela capaz de "incorporar a questão do Significado e da Intencionalidade como inerente aos atos, às relações e às estruturas sociais, sendo essas últimas tomadas tanto no seu advento, quanto na sua transformação, como construções humanas significativas" (MINAYO,1992, p.10).

Para RAMOGNINO (1982), um trabalho de conhecimento tem que atingir três dimensões, a simbólica, a histórica e a concreta. A dimensão simbólica contempla os significados dos sujeitos; a histórica, privilegia o tempo consolidado do espaço real e analítico e a concreta se refere às estruturas e aos atores sociais em relação.

Concordamos com MINAYO (1992), que a compreensão do indivíduo como representativo tem que 
ser completada pelas variáveis próprias, tanto da especificidade histórica como dos determinantes das relações sociais e também, dentro do próprio grupo ou comunidade alvo da pesquisa, com uma diversificação que contemple as hipóteses, pressupostos e variáveis para compreensão do objeto.

\section{Campo de estudo}

A pesquisa foi realizada apenas em uma Unidade dentro da área geográfica onde o PROASE se desenvolve o Distrito Central.

O Distrito Central compreende seis (06) Unidades Básicas de Saúde (UBS) além da própria Distrital. As unidades do distrito são as seguintes:

1. UBS Vila Tibério

2. CSE Vila Tibério

3. UBS Hélio Lourenço de Oliveira - Santa Cruz

4. UBS Área Materno Infantil

5. UBS Central (Setor Pediatria)

6. UBS Central (sendo reformada)

Dentre as seis Unidades Básicas, desenvolvemos o nosso trabalho na UBS Central (Setor Pediatria) onde estão alocados os profissionais do PROASE. Esta UBS abrange os sub-setores N-1 e L-1 e o Setor C e compreende $5.83 \mathrm{~km}^{2}$.

Assim escolhemos a Unidade 5, onde é atendida somente a população infantil, a qual funciona 24 horas, com abertura de prontuário para crianças residentes na área de abrangência. Para as não pertencentes à área, é feito o primeiro atendimento e o encaminhamento para a Unidade mais próximas de sua residência.

Como a Unidade funciona durante 24 horas, a população de todo o município pode ser atendida nessa UBS. Para as crianças do município existe referência nas áreas de Cardiologia, Gastroenterologia Genética, Neurologia, Hebeatria e para os escolares existe a referência nas áreas de Psicologia e Fonoaudiologia somente para escolas que pertencem à área de abrangência desta UBS.

A escolha dessa área para o desenvolvimento do trabalho deveu-se, principalmente, por ser a mesma, o primeiro local que implantou o Ambulatório de Saúde Escolar, e por ser uma Unidade de Saúde que tem suas atividades voltadas especificamente para a criança, contando com diferentes tipos de atendimento.

A Unidade possui os seguintes "setores": marcação de consulta, recepção de enfermagem, consultórios médicos, terapia e reidratação oral (TRO), doenças respiratórias na infância (DRI), imunização, sala de curativos contaminados, sala de curativos não contaminados, farmácia, consultório odontológico, assistência social e ambulatórios do Programa de Assistência Primária de Saúde Escolar (PROASE).
Atuam na Unidade vinte pediatras que se revezam por turnos de quatro horas, no período das 7:00 às 19:00h. No horário de 19:00 às 7:00h, o posto funciona no sistema de plantão com pediatras da prefeitura.

Os pediatras, que atendem casos de rotina, realizam dezesseis consultas por período. A pediatria do PROASE atende oito casos de retorno para seguimento no Programa, e dois novos casos agendados (as consultas de casos novos levam, em média, 50 minutos a uma hora).

No ambulatório do PROASE são atendidas crianças encaminhadas pelos médicos da Unidade, pelas escolas ou por demanda espontânea. O PROASE atende crianças na faixa etária de 06 anos à 12 anos, pertencentes à área de abrangência do PAM II (Área Central).

As crianças passam por uma triagem com um pediatra do Programa, de onde podem ser encaminhadas para o setor de psicologia ou fonoaudiologia, ou até mesmo continuar em acompanhamento com o pediatra. $\mathrm{O}$ PROASE conta com um pediatra, duas fonoaudiólogas e três psicólogas.

\section{Trabalho de campo}

Como componente do trabalho de campo, elegeuse a técnica de entrevista semi-estruturada e a análise documental como instrumento de coleta de material. A entrevista seguiu um roteiro que combinou questões fechadas e abertas sendo classificada como semiestruturada por Honningmann (MINAYO, 1992).

Como sujeitos de nossa investigação, elegemos três segmentos da sociedade envolvidos no processo: a família dos escolares, os profissionais da educação que trabalham diretamente com eles e os profissionais da saúde que são procurados para dar atendimento a essa população.

As famílias dos escolares foram selecionadas através de um sorteio entre as crianças atendidas no Programa de 1992 e a entrevista realizou-se no próprio domicílio. Foram feitas dez (10) entrevistas com as famílias, sendo cinco (05) mães, dois (02) pais, uma (01) avó, uma (01) tia e um (01) avô.

Quanto aos profissionais da área de educação (delegados de ensino, diretores, coordenadores do ciclo básico, orientadora pedagógica), procedeu-se a um sorteio das escolas da área de abrangência. A pesquisa foi realizada no próprio local de trabalho e, ao todo, foram entrevistados 09 (nove) profissionais sendo 02 (dois) delegados de ensino, 02 (dois) professores, 02 (dois) diretores, 01 (uma) orientadora educacional, 01 (uma) coordenadora pedagógica e 01 (uma) coordenadora do ciclo básico.

$\mathrm{Na}$ área da saúde, foram entrevistados trabalhadores que atuam no Programa, na Unidade Básica Central - Setor Pediatria. A pesquisa foi realizada, no 
próprio local de trabalho, com 08 (oito) profissionais, sendo 01 (uma) com pediatra, 02 (duas) com fonoaudiólogos, 02 (duas) com psicólogas, 01 (uma) com assistente social, 01 (uma) com enfermeira e 01 (uma) com auxiliar de enfermagem. Portanto, o número total de agentes sociais entrevistados correspondem a 27.

As entrevistas foram gravadas, após obter-se a aquiescência do entrevistado e posteriormente transcritas. Tiveram duração média de 30 minutos, porém algumas atingiram 50 minutos de gravação.

Cumpre salientar que as entrevistas foram todas realizadas pessoalmente pela pesquisadora, bem como a observação participante.

\section{ANÁLISE DOS DADOS}

No sentido de melhor compreendermos os dados de nossa investigação, nos inspiramos na proposta hermenêutica-dialética, sistematizada por MINAYO (1992). Sem seguirmos integralmente esta proposta, adotamos como procedimento de análise, estabelecer confrontos em diferentes níveis de análises; confronto entre as falas dos diferentes atores sociais envolvidos; confronto entre estas falas com o discurso oficial do PROASE, contemplando, assim, um dos princípios propostos pela autora citada.

Utilizamos quatro esquemas que retrataram os quatro momentos de análise: (1) análise dos depoimentos dos profissionais da saúde; (2) dos depoimentos dos profissionais da educação; (3) dos depoimentos dos familiares; (4) confronto entre os depoimentos dos diferentes atores sociais.

Finalmente, procuramos articular as nossas conclusões com o nosso pressuposto, à luz da fundamentação teórica, na busca de respostas para as perguntas do nosso estudo. Toda a nossa trajetória de análise, através de sucessivos confrontos, procurou refletir sobre as relações entre a prática do atendimento e o discurso oficial do PROASE.

Os dados levantados na parte inicial da entrevista consistem de uma primeira aproximação com os sujeitos sociais no intuito de apresentá-los, assinalando de quem são essas percepções.

Os sujeitos sociais entrevistados, na área da saúde, são profissionais de diversas áreas (pediatria, fonoaudiologia, psicologia, assistência social e enfermagem). Em relação à faixa etária, estes se encontram na faixa de 26 a 36 anos, sendo apenas um dos entrevistados com 61 anos de idade. O tempo de atividade profissional, varia desde dois anos e seis meses até 17 anos de exercício profissional, destacando 01 (um) profissional com 34 anos de serviço; o tempo de serviço do profissional na Secretaria Municipal da Saúde, especificamente no PROASE, varia de 01 (um) ano a 5 (cinco) anos.

A maioria dos profissionais tem uma carga horária correspondente a 20 horas semanais e alguns têm outro emprego. $\mathrm{O}$ pediatra dedica apenas 08 horas semanais para o PROASE, bem como 01 (uma) assistente social, que presta serviço na Unidade e colabora, também, com o Programa nos momentos em que há necessidade e participa das reuniões semanais com os demais profissionais.

Apenas 01 (um) dos entrevistados não foi admitido por concurso e todos passaram por um treinamento com a coordenação do PROASE antes de iniciarem suas atividades no Programa. A formação da maioria desses profissionais é clínica, tendo apenas 01 (um) com formação em saúde pública.

Quanto aos profissionais da educação, estes encontram-se na faixa etária que vai de 26 a 64 anos. O tempo de carreira varia de 03 anos e seis meses até 30 anos de magistério; estes profissionais ocupam cargos e atividades diferentes no âmbito educacional e trabalham, na maioria, em um só local, exceto a categoria de professor, que ministra aulas em mais de uma escola. $\mathrm{O}$ grupo de profissionais entrevistados na Educação pertencem a mesma área de abrangência em que o Programa vem se desenvolvendo, exceto 02 dos entrevistados que são os Delegados de Ensino que representam o ensino público estadual do município de Ribeirão Preto.

Quanto aos familiares dos escolares entrevistados, observa-se que é um grupo heterogêneo no que se refere aos aspectos sociais, culturais e econômicos.

A idade deste grupo vai desde 29 até 71 anos de idade. A maioria dos sujeitos sociais não tem o $1^{\circ}$ grau completo, exceto um que fez o $2^{\circ}$ grau e outro que tem o $3^{\circ}$ grau completo.

Observamos que a maioria das famílias tem rendimentos mensais entre 3 e 5 salários mínimos, exceto 2 (duas) famílias cuja renda varia de 5 a 10 salários mínimos e uma família com mais de 10 salários mínimos. A média de pessoas na família situa-se entre 04 (quatro) e 06 (seis).

No sentido de melhor compreendermos o significado do Fracasso Escolar para os atores sociais que utilizam o PROASE, escolhemos os seguintes aspectos de análise, observados na fala dos sujeitos sociais entrevistados:

- Perfil da criança atendida

- Motivos de encaminhamento

- Fracasso escolar 
De acordo com a síntese dos depoimentos dos três grupos entrevistados (profissionais da saúde, educação e família), observa-se que o perfil da criança atendida se caracteriza de forma semelhante para os profissionais da saúde e educação, ou seja, as crianças provêm de famílias desestruturadas, com problemas sociais, financeiros, culturais e desprivilegiadas (pais separados, mãe solteira, pais alcoólatras e presidiários) e ainda crianças com problemas físicos, nutricionais, emocionais e de aprendizagem.

As características do perfil da clientela encontrada em nosso estudo é semelhante ao que a literatura vem apontando. MOYSÉS \& COLLARES (1993) chama a atenção para o cotidiano escolar que é permeado de preconceitos e juízos prévios, sobre os alunos e suas famílias. As crianças não aprendem porque são pobres, porque são negras, são imaturas, preguiçosas, seus pais são analfabetos, são alcoólatras, as mães trabalham fora. Por outro lado, MATURANO et al. (1992) enfatiza que não podem ser descartados, nesse enorme contingente de crianças, os casos isolados que requerem suporte profissional especializado. Nessa linha de pensamento, SANTOS (1990) afirma que o "diagnóstico realizado evidencia, na maioria das vezes, problemas de natureza eminentemente emocional, encobertos pelas queixas escolares".

Retomando a trajetória do PROASE no município de Ribeirão Preto, observamos que o fato de os profissionais terem, no início do programa, desenvolvido suas atividades no espaço escolar, fez com que os mesmos diferenciassem os problemas de caráter pedagógico, dos problemas de saúde, que podem acarretar prejuízo à aprendizagem. Dessa forma, foi possível acompanhar a criança no contexto educacional e famíliar, o que facilitou conhecer a história de vida da criança, evitando-se a medicalização e a patologização nas Unidades Básicas.

Para as famílias, os filhos são crianças normais, inteligentes, mas com problemas de ordem biológica (visão, fala) e problemas emocionais e de aprendizagem, dissociados dos fatores estruturais e conjunturais da própria família, da sociedade, do sistema educacional e do sistema de saúde, dentre outros.

\section{Motivos de encaminhamento}

O motivo de encaminhamento destas crianças está relacionado a:

- problemas biológicos

- problemas de aprendizagem

- problemas de comportamento

- problemas emocionais

- crianças de famílias desestruturadas
Estes encaminhamentos foram realizados por profissionais da educação, saúde ou por procura espontânea, principalmente por membros da família interessados em saber como lidar com a criança em idade escolar. Observamos que a procura pelos serviços médicos, por familiares que buscam orientações sobre a fase de escolarização, tem aumentado muito.

De acordo com COLLARES \& MOYSÉS (1985), pouquíssimas escolas de medicina no Brasil incluem, em seu currículo, mesmo na especialização em Pediatria, o conhecimento da criança em idade escolar, seja em termos de desenvolvimento cognitivo, seja em termos de saúde física. De fato, podemos constatar, em nossa prática diária, o despreparo dos profissionais, não só desta área como das outras, para lidar com essa questão.

Analisando a proposta do PROASE, verificamos que estes dois aspectos vêm sendo contemplados na prática. Está previsto atendimento a crianças de 5 a 14 anos, da rede de ensino público do município de Ribeirão Preto, com problemas de ordem física (visual, auditiva, fala) de aprendizagem, de comportamento, deficiência mental e problemas familiares. A proposta recomenda que o encaminhamento destes deve ser feito pelos profissionais da saúde, da educação ou pelos familiares.

\section{Significado do fracasso escolar}

No que se refere ao fracasso escolar, percebemos que este é visto, pelos profissionais da saúde como reflexo da situação social que engloba aspectos da família, escola e ensino.

Para estes, o aspecto "problema familiar" advém do baixo poder aquisitivo, das condições inadequadas e precárias de vida e da questão de pais separados.

Quanto ao ensino, ressaltam que a dificuldade não é exclusiva da criança e chamam a atenção para a falta de uma adaptação adequada à metodologia utilizada e para o despreparo de muitos professores. As classes são numerosas, dificultando o trabalho do professor, que fica impossibilitado de oferecer um atendimento individualizado às crianças. Dessa forma, ele não tem condições de conhecer a história de vida da criança e passa a focalizar apenas seus aspectos negativos, conforme os seguintes depoimentos:

"...focaliza-se mais atenção nos problemas

do que nos aspectos positivos, no sucesso" (E-II-Saúde).

“... a culpa não é das crianças. A maneira de como é cobrado da criança e é ensinado a criança. A escola acaba sendo vista como castigo" (E-IV-Saúde).

A proposta do Programa de trazer os professores para participar do grupo de discussão dos casos 
encaminhados das escolas e atendidos no ambulatório tem o propósito de desmistificar o fracasso escolar, procurando sensibilizar o professor para uma reflexão mais profunda da questão, apontando a importância de um maior envolvimento e integração entre os profissionais dessas duas práticas sociais Saúde-Educação que lidam com o mesmo objeto de trabalho.

Observamos que a Saúde procura mostrar os seus limites aos professores e que o envolvimento tem que ser tanto da Educação quanto da Saúde.

Entre as falas que representam estas inquietações, destacamos a seguinte:

“...tem que ter um pouco de preparo, não é a criança que tem a dificuldade escolar, mas é o método que a professora tem é que tem que mudar, conversando com as crianças, ver os antecedentes. A dificuldade não é da criança é do professor..."(E-VI-Saúde).

Para os profissionais da Educação, o fracasso escolar está centrado na criança e na família:

"São vários fatores provenientes das condições em que vivem essas crianças, quer a nível sócio-econômico, cultural, quer a nivel de estrutura familiar e também a desinformação dos pais quanto a estimulação da criança e do que consideram prioridades (comer, sobreviver)" (E-IV-Educação).

Apesar disso, os profissionais da educação admitem que o fracasso escolar está relacionado também aos fatores educacionais:

"Fracasso Escolar, depende até do trabalho da escola, e um acompanhamento da saúde escolar como é realizado no PROASE”.). $(E-$ II-Educação).

"Cada professor segue um método, uns o construtivismo, outros o tradicional”.). EVIII-Educação).

"Há uma outra corrente que acredita ser o professor o maior responsável pelo FRACASSO ESCOLAR. Acreditam que estudando Piaget vai resolver os problemas destas crianças com o construtivismo, sem a valorização da sala de aula. Dizer que o problema é só da educação é panacéia, precisa, sim, haver integração. Acho que é um problema politico educacional”.(E-IVEducação).

PATTO (1990), ao analisar longitudinalmente a estrutura do discurso de cada uma das educadoras entrevistadas sobre a causa do FRACASSO ESCOLAR, revela, em síntese, que sua principal característica é uma superposição de explicações contraditórias para o FRACASSO ESCOLAR, na qual a falta de condições do professor para ensinar convive com a convicção de que os que não aprendem o fazem por falta de condições individuais. Os depoimentos constituem-se de uma sucessão de pensamentos estanques, carregados de preconceitos e estereótipos que momentos de uma visão mais crítica não conseguem abalar.

Concordamos com a autora, pois durante todos esses anos, constatamos, na prática, que as dificuldades de aprendizagem das crianças, para os profissionais da educação, são explicitamente atribuídas a algum distúrbio centrado ou na criança ou na família e estes devem,logo, ser encaminhados ao serviço de saúde.

Para MOYSÉS \& COLLARES (1993), este processo de biologização geralmente se manifesta, colocando como causas do fracasso escolar quaisquer doenças das crianças e deslocando-se o eixo de uma discussão político-pedagógica para causas e soluções pretensamente médicas, portanto inacessíveis à Educação. A isto temos chamado medicalização do processo ensino-aprendizagem. Pelo fato de outros profissionais da área da saúde também estarem envolvidos com o mesmo objeto, não mais só o médico, as autoras têm utilizado a expressão patologização do processo ensino aprendizagem.

Todavia, os profissionais da saúde acreditam que o problema não está centralizado somente no professor, mas também na estrutura educacional.

"A professora não tem condições de dar atendimento individual, as classes numerosas acabam dificultando" (E-VIIISaúde).

Assim, percebemos uma dicotomia de pensamento entre os profissionais dessas duas práticas sociais, cada um querendo se isentar da responsabilidade. Quanto às famílias, concordamos com PATTO (1990), que estas tendem a repetir a versão ideológica sobre os determinantes do fracasso escolar, que tem nas próprias educadoras suas principais porta-vozes por ocasião de reuniões de pais, ou de contatos mais informais com os familiares de crianças que não estão correspondendo as expectativas.

Podemos observar nos depoimentos abaixo: "É em relação a criança porque a cabeça não ajuda."(E-II-Família).

"A criança não presta atenção e não consegue aprender. (E-X-Família).

"Crianças imaturas que não conseguem aprender e repetentes. (E-V-Família).

Portanto, as colocações das mães repetem o discurso do professor. Uma entrevistada, com grau de escolaridade superior às demais, embora relacione o Fracasso Escolar ao Sistema Educacional, deixa transparecer, em sua fala, que o problema é pedagógico.

"A professora passa lição muitas vezes para 
frente, sem a criança saber que é realmente importante ela ter conhecimento do que é real."(E-I-Família).

$\mathrm{O}$ que percebemos, numa primeira análise do discurso das mães, é uma repetição literal do que as professoras dizem, entretanto, esta característica não nos permite avaliar o nível de percepção delas acerca das dificuldades escolares de seus filhos. Essas mães, após algumas justificativas, deixam transparecer uma mensagem de perplexidade diante do fracasso escolar dos filhos.

Observamos na fala dos 03 (três) grupos de entrevistados, que o fracasso escolar não tem a mesma conotação entre eles e o discurso que mais se aproximou do Programa foi o dos profissionais da saúde.

Dados referentes ao movimento escolar da rede estadual de ensino no ano de 1990, no Estado de São Paulo, apontam que são bastante significativos os índices das perdas escolares ao longo do $1^{\circ}$ grau em relação a evasão e repetência, ou seja:

$8,8 \%$ dos escolares que ingressaram no $1^{\circ}$ grau evadiram no $1^{\circ}$ ano, ou seja, no Ciclo Básico Inicial;

$6,7 \%$ evadiram no decorrer do $2^{\circ}$ ano, ou seja, do Ciclo Básico Continuidade;

$27 \%$ foram retidos por avaliação ou por freqüência ao final do Ciclo Básico Continuidade;

Portanto apenas $57,6 \%$ dos que passaram pelo Ciclo Básico após 2 anos seguiram cursando a $3^{a}$ série;

$O$ número de matrículas na $8^{a}$ série do $1^{\circ}$ grau representa $40 \%$ do número de escolares matriculados no Ciclo Básico. $O$ número de escolares que concluíram a $8^{a}$ série, ou seja, o $1^{\circ}$ grau, representa 29,6\% do número de matrículas no Ciclo Básico Inicial, o que indica que foram excluídos do Sistema de Ensino, por evasão ou retenção ao longo do $l^{\circ}$ grau, 70,4\% dos escolares que nele ingressaram.(SÃO PAULO, 1993, p.5).

Observamos que o sistema educacional, apesar dos esforços desenvolvidos ao longo da história, continua não atingindo aos objetivos a que se propõe, ou seja, continua atribuindo de forma simplista o insucesso das crianças às más condições da clientela.

Nessa linha de pensamento algumas pesquisas recentes - PATTO (1990); MOYSÉS \& COLLARES (1993) - vêm apontando preconceitos e estereótipos sobre a criança advinda de famílias pobres, seja pela separação dos pais, seja por sua ausência, seja por defeitos morais e psíquicos.

Em estudo anterior FERRIANI (1991) buscou conhecer através da literatura específica os vários projetos educacionais propostos ao longo da história, desde o século XVIII até os dias atuais, ou seja, o Ciclo Básico, que emerge no Estado de São Paulo, criado com o objetivo de evitar repetência e, conseqüentemente, a evasão escolar. Inúmeros projetos e decretos buscaram minimizar os problemas da educação. Entretanto, o elitismo, a contradição e a instabilidade têm sido, como vimos na literatura consultada, as características das mudanças no setor educação.

Atualmente, verificamos o surgimento de uma nova proposta educacional no Estado de São Paulo que é referente as Escolas-padrão.

Esta proposta, considerada revolucionária pelo atual governo, já foi implantada em 1600 escolas e 250 mil professores já freqüentaram, nos últimos três anos, mais de sete mil cursos nos Centros de Aperfeiçoamento de Recursos Humanos. Os professores trabalham em regime de dedicação exclusiva e recebem $30 \%$ a mais de salários para proporcionarem melhor qualidade de ensino a seus alunos. As escolas são contempladas com um moderno sistema de complementação didática, laboratórios equipados, computadores, equipamentos de vídeo cassete, biblioteca, etc.

Outra preocupação do atual governo refere-se à melhoria da merenda escolar, com o objetivo de diminuir a incidência de anemia e avitaminose A.

Em síntese, são muitas as variáveis determinantes do rendimento escolar. No geral, as questões relacionadas ao fracasso escolar reunem tal complexidade que se torna impossível apreendê-las e explicá-las linearmente. É necessário estimular os professores e os pais a refletirem sobre estas questões discutidas no texto e montar estratégias mais efetivas no setor educacional tais como seu próprio projeto pedagógico; uma maior integração entre as Secretarias de Saúde e de Educação, ter um espaço oficial na Secretaria Municipal da Educação, para que os professores possam participar das reuniões propostas pelo Programa e com isto garantir maior integração da escola, profissionais da saúde e família.

\section{CONSIDERAÇÕES FINAIS}

Retomando o nosso objetivo de identificar, conhecer e analisar o significado do fracasso escolar para os atores sociais que utilizam o PROASE (pais, profissionais da educação e da saúde que atuam no Programa) verificamos que o perfil da criança atendida e os motivos de encaminhamento se caracterizam de forma semelhante para os profissionais da saúde e educação, bem como o que a literatura vem apontando, permeado de preconceitos sobre os alunos e as famílias. 
O fracasso escolar é visto pelos profissionais da saúde como reflexo da situação social que engloba aspectos da família, escola e ensino. A proposta de trazer os professores para participar das discussões sobre os casos encaminhados, com o propósito de desmistificar o fracasso escolar, é uma estratégia que sensibilizou o professor para uma reflexão mais aprofundada da questão.

Para os profissionais da educação, o fracasso escolar está centrado na criança e na família. Assim, percebemos uma dicotomia de pensamento entre os profissionais desses dois setores, cada um querendo se isentar da responsabilidade.

As famílias apresentam um discurso mesclado, com ênfase na versão ideológica sobre os determinantes do fracasso escolar; concomitantemente têm nos educadores seus principais porta-vozes, por ocasião das reuniões.

Destacamos, ainda, nas falas dos três grupos entrevistados, que o fracasso escolar não tem a mesma conotação entre eles. Entendemos que essa divergência tem sido constatada durante todo o processo de reflexão que a equipe multiprofissional vem desenvolvendo desde a implantação do PROASE.

\title{
MEANING OF SCHOOL FAILURE TO SOCIAL ACTORS WHO USE THE PROGRAM OF SCHOOL HEALTH PRIMARY CARE - PROASE AT THE MUNICIPALITY OF RIBEIRÃO PRETO
}

The present study has the purpose to identify and analyze the meaning of school failure to social actors that use or work in the Program of School Health Primary Care - PROASE (family members, health and education professionals) and to articulate their discourse with the official discourse in order to establish the program's future actions. Our study has a qualitative theoretical framework based in Minayo (1992). One area where PROASE develops its activities was chosen and by semistructured interviews and documentation analysis it was possible to know how the three segments that compose the sample understand the meaning of school failure.

KEY WORDS: low outcomes at school, health occupations, school students, nursing

\section{SIGNIFICADO DEL FRACASO ESCOLAR PARA LOS ACTORES SOCIALES QUE UTILIZAN EL PROGRAMA DE ASISTENCIA PRIMÁRIA DE SALUD ESCOLAR “PROASE” EN EL MUNICIPIO DE RIBEIRÃO PRETO}

\begin{abstract}
El presente trabajo tiene como objetivo identificar y analizar el significado del fracaso escolar para los actores sociales que utilizam el PROASE - Programa de Asistência Primária del Salud Escolar (familiares, profesionales de educación y salud) articulando el discurso de esos actores con el discurso oficial, con planes de conceder subsidiayudas para futuras acciones para el Programa. Como referencial teórico fue utilizado un enfoque cualitativo, fundamentado en Minayo (1992). Fue elegida el área en que el PROASE desarrolla sus actividades, y a través de la técnica de entrevista semi estructurada y análisis de documentos, fue posible conocer e identificar la forma como los tres segmentos que hacen parte de la muestra (familia, profesionales de educación y salud) entiendem el significado del fracaso escolar.
\end{abstract}

TÉRMINOS CLAVES: bajo rendimiento escolar, ocupaciones en salud, escolares, enfermería

\section{REFERÊNCIAS BIBLIOGRÁFICAS}

01. COLlARES, C.A.L.; MOYSÉS, M.A.A. O renascimento da saúde escolar legitimando a ampliação do mercado de trabalho escolar. In: CENTRO DE ESTUDOS EDUCAÇÃO E SOCIEDADE (org.). O sucesso escolar: um desafio pedagógico. Campinas: Papirus, 1992. p.23-29 (cadernos CEDES-28).

02. COLLARES, C.A.L.; MOYSÉS, M.A.A. Educação ou Saúde? Educação X Saúde? Educação e Saúde? Cadernos CEDES, n.15, p. 7-16, 1985.
03. FERRIANI, M.G.C. A inserção do enfermeiro na saúde escolar. São Paulo: EDUSP, 1991. (Coleção Campi, v.3).

04. FERRIANI, M.G.C.; CANO, M.A.T. Proposta do PROASE. Plano Diretor de Saúde - 1992. São Paulo/Apresentado à Secretaria Municipal da Saúde de Ribeirão Preto e Escola de Enfermagem de Ribeirão Preto da Universidade de São Paulo, 1992. 28p./mimeografado/.

05. FERRIANI, M.G.C.; GOMES, R. Saúde escolar: contradições e desafios. Goiânia: AB Editora, 1997. 
06. FUNDAÇÃO IBGE. Anuário estatístico do Brasil, rio de Janeiro, 1992.

07. HARADA, J. Avaliação das atividades médicoassistenciais do Programa de Saúde Escolar numa Unidade Básica de Saúde no Embú. São Paulo, 1993. 108p. Dissertação (Mestrado) Escola Paulista de Medicina.

08. KNOBEL, M. Orientação familiar. Campinas: Papirus, 1992.

09. MATURANO, E.M.; MAYNA, J.M.; MURTHA, P.E. Contribuição do diagnóstico das dificuldades de aprendizagem escolar. Rev. Psicopedagog., v.11, n.24, p. 23-24, 1992.

10. MINAYO, M.C.S. O desafio do conhecimento: pesquisa qualitativa em saúde. São Paulo: HUCITEC/ABRASCO, 1992. 269p.

11. MINAYO, M.C.S.; SANCHES, O. Quantitativoqualitativo: oposição ou complementariedade? Cad.Saúde Pública, Rio de Janeiro, v.9, n.3, p.239-62, jul./set. 1993.

12. MINUCHIN, S. Famílias: funcionamento e tratamento. Porto Alegre: Artes Médicas, 1990.

13. MOYSÉS, M.A.A.; COLLARES, C.A.L. Sobre alguns preconceitos no cotidiano escolar. IDÉIAS, v.19, p. 2-25, São Paulo, 1993.
14. PARKER, R.G. Corpos, prazeres e paixões: a cultura sexual no Brasil contemporâneo. São Paulo: Best Seller, 1991.

15. PATTO, M.H.S. A produção do fracasso escolar: histórias de submissão e rebeldia. São Paulo: T.A. Queiroz, 1990.p. 385.

16. PROJETO PREVÊ reduzir índice de repetência. Folha de São Paulo, São Paulo, 17 maio de 1996, p. 8, caderno 7.C.

17. RAMOGNINO, N. Pour une approche dialectique in sociologie. Sociologie et Societés, v. 59, p. 8386, 1982.

18. SANTOS, M.A. Caracterização de uma clínica psicológica da Prefeitura de São Paulo. Arq. Bras. Psicol., v.42, n.2, p.79-94, 1990.

19. SÃO PAULO (Estado). Secretaria de Estado de Saúde. Grupo de Atenção à Saúde Mental. CADAIS. Núcleo Técnico de Saúde mental. CADASE/DAE. Secretaria de Estado de Educação Especial. CEMP. Reflexão sobre uma atuação conjunto Saúde - Educação frente á saúde mental do escolar de $1^{\circ}$ grau. São Paulo, Secretaria de Estado de Saúde, 1993, p. 16, (mimiografado). 